\title{
Stress and recovery in junior doctors
}

\author{
Elke Ochsmann, ${ }^{1,2}$ Jessica Lang, ${ }^{1}$ Hans Drexler, ${ }^{2}$ Klaus Schmid ${ }^{2}$
}

${ }^{1}$ Institute of Occupational and Social Medicine, Medical Faculty, RWTH Aachen University, Germany ${ }^{2}$ Institute of Occupational, Social and Environmental Medicine, University of Erlangen-Nuremberg, Germany

Correspondence to Dr Elke Ochsmann, Institute of Occupational and Social Medicine, Medical Faculty, RWTH Aachen University, Pauwelsstrasse 30, D-52074 Aachen, Germany: eochsmann@ukaachen.de

Received 27 May 2010 Accepted 15 January 2011 Published Online First 24 March 2011

\begin{abstract}
Objective Junior doctors are thought to experience increased mental strain in comparison to other occupations. The aim of the present study was to analyse selected work related influencing factors of strain and recovery in junior doctors.
\end{abstract}

Methods In September 2006, 1494 young doctors were asked to participate in a postal questionnaire study featuring the Recovery Stress Questionnaire (RESTO) and additional questions on job specific risk factors. Using hierarchical linear regression analyses the answers of 637 participants with less than 1.5 years work experience in patient care were analysed.

Results Results revealed that overtime work, as well as lack of performance related feedback from supervisors, were consistently related to increased levels of strain among junior doctors. These risk factors were also predominantly related to recovery. In addition, feedback from colleagues was significantly associated with the recovery sub-scales (except with sleep quality).

Conclusions Overtime work and performance related feedback from supervisors seem to be important work related factors concerning junior doctors' levels of strain and recovery. In addition, performance feedback from colleagues seems to be a major resource for recovery. The findings have implications regarding work time regulations and the necessity of leadership skill development training regarding feedback talks and fostering a desirable social climate in the healthcare system for the wellbeing of junior doctors.

\section{BACKGROUND}

Strain levels in doctors have been assessed for several decades and were found to be associated with individual (eg, personality traits) and job related factors (eg, working hours). ${ }^{1}{ }^{2}$ The main stressors were overtime, long work hours, shift work as well as lack of support from senior staff and colleagues (for an overview see Tyssen and Vaglum $^{2}$ ). Despite regulatory approaches (eg, the European Directive concerning certain aspects of the organisation of working time), strain levels in doctors have remained relatively constant over time. Specifically, $28 \%$ of doctors and other health professionals fulfil the criteria for a mental health disorder, as measured by the General Health Questionnaire, in comparison to $18 \%$ of the general working population. ${ }^{3}$ Since mental health problems are related to reduced job performance, which is especially critical in healthcare professionals, it is important to understand the factors related to increased strain for designing effective interventions. ${ }^{4}$

Increased work stress and strain in health professionals has been reported to be especially evident in junior doctors. ${ }^{56}$ Their levels of emotional distress have been regarded as 'unacceptably high', with the highest levels among doctors in their first postgraduate year. ${ }^{7}$ Stressors related to overwork seem to be a predominant risk factor. Similarly, leadership skills and supervisory behaviour have been frequently reported to be a relevant factor regarding employee health (eg, insomnia) and wellbeing. ${ }^{8}$ Confronting these stressors requires an increased amount of individual effort and energy expenditure and a loss of valuable resources. According to the Conservation of Resources Theory, stress and strain are not only dependent on the amount of demands that are placed on the individual, but occur if individuals additionally experience loss of resources (ie, the capacity to deal with stressors). ${ }^{9}$ Therefore, stressors, such as overtime, are not only an indicator of increased job demands but are also accompanied by a lack of time for individual recovery. During recovery individuals re-establish resources after they have been taxed by stressors. ${ }^{10}$

Working overtime by definition reduces the possibility of recovery. When individual resources are depleted due to insufficient recovery, the imbalance of a demanding work situation and under-recovery will cause emotional, health related, and performance decrements. ${ }^{11}$

Because of the high relevance of both experienced strain and recovery in the development of long term psychological and physical health effects, it is important to assess these factors simultaneously in the context of possible work stressors. Previous research on junior doctors' stress levels has not considered this. Therefore, the aim of the present study was to analyse the relationship between relevant job stressors and job related strain-recovery states in junior doctors, who we already know from previous research are especially prone to experiencing stress and mental disorders. We hypothesise that different workplace factors influence aspects of stress and recovery, differently. The results of this investigation might be used to deduce recommendations for the prevention of stress and for the support of recovery in junior doctors.

\section{METHODS \\ Study design and participants}

In September 2006 we mailed an invitation letter and questionnaire to 1494 junior doctors who were registered as approbated doctors in Bavaria for the first time in 2005. The invitations were forwarded in cooperation with the Bavarian Medical Board Register. Participants were informed about the study's contents and that their responses would be treated confidentially. The responding doctors were most likely to have work experience of between 1.5-2 years. Between September 2006 and March 2007, altogether 792 doctors responded to our 
invitation by sending back the filled in questionnaire anonymously. Out of the returned questionnaires only clinically working young doctors were included for the present analysis, which focuses on the influence of workplace factors on strain and recovery. All the junior doctors provided informed consent.

\section{Measures}

Recovery-stress questionnaire (RESTQ)

The RESTQ ${ }^{10}{ }^{12}$ is a psychometrically based instrument for assessing the recovery-strain state of individuals. ${ }^{13}$ It allows derivation of a profile of individual strain and recovery within the past 3 days by a self-report approach. Its multidimensional conception addresses different domains of strain and recovery including physical, subjective (emotional, mood related), behavioural (performance related), and social aspects. The RESTQ detects the frequency of activities related to stress and recovery according to seven strain and five recovery sub-scales. The short form $24 \mathrm{~A} / \mathrm{R}$ of the RESTQ, which was used here, consists of two items per sub-scale and one warm-up question. For assessing strain, the relevant sub-scales are: general stress (RESTQ1), emotional stress (RESTQ2), social stress (RESTQ3), conflict (RESTQ4), fatigue (RESTQ5), lack of energy (RESTQ6), physical complaints (RESTQ7); for recovery the following subscales are included: success (RESTQ8), social recovery (RESTQ9), physical recovery (RESTQ10), general wellbeing (RESTQ11), and sleep quality (RESTQ12). The questions were answered according to their frequency on a Likert-like scale ranging from 0 (never) to 6 (always), which indicates how often respondents have participated in various activities over the last 3 days, where higher scores reflect higher activities in the respective areas.

\section{Workplace specific risk factors}

We assessed workplace specific risk factors regarding the amount of working time and performance related feedback. Aspects of working time were measured with three individual questions: (1) overtime per week (five point response scale; 1: none, 2: 1-2 h, 3: 3-5 h, 4: 6-10 h, 5: >10 h); (2) night-shifts per month (four point response scale; 1 : none, 2: 1-3 shifts, 3: 4-7 shifts, 4: $\geq 8$ shifts); (3) weekend duty (days) per month (five point response scale; 1: none, 2: 1-2 days, 3: 3-4 days, 4: 5-6 days, 5: 7-8 days). Aspects of performance feedback were measured with two individual questions: (1) feedback from supervisors; and (2) feedback from colleagues according to the question: "How often does your nearest superior/do your colleagues talk with you about how well you carry out your work?" (both items were adopted from the Copenhagen Psychosocial Questionnaire (COPSOQ $)^{14}$; five point response scales ranged from $1=$ never to $5=$ always).

\section{Control variables}

All analysis controlled for the following personal factors, as they are generally considered as possible confounders for strain and recovery scores: age, sex, personal living conditions (living alone vs living together), and children under the age of 15 living in the household (yes vs no).

\section{Statistical analysis}

All calculations were conducted using SPSS 16. For evaluating the independent influence of work related risk factors regarding time (ie, overtime, nightshift, weekend duty) and social climate (ie, performance feedback from supervisors and colleagues) on the respective strain and recovery sub-scales of the RESTQ, we conducted hierarchical regression analyses for each of the 12 sub-scales. In the first step, the control variables (age, sex, personal living conditions, and children) were entered. In the second step, all independent workplace risk factors were entered into the regression equation. Thus, the analyses allow us to estimate the relative influence of each risk factor for strain and recovery, respectively.

\section{RESULTS}

\section{Descriptive statistics}

Altogether 637 (55.8\% female) junior doctors were included in the present analysis (age range 26-50 years; mean $\pm \mathrm{SD}$ : $28.9 \pm 2.4$ years; response rate: $53 \%$ ). Most of the participants live with a partner $(\mathrm{n}=367 ; 58.7 \%)$, and without children under 15 years ( $\mathrm{n}=548$; 88.7\%). Overall, 420 junior doctors $(66.8 \%)$ work $\geq 6$ h overtime per week, 316 (50.3\%) reported $\geq 4$ days of nightshift per month, and 250 (39.9\%) work more than one weekend per month on weekend duty. Regarding feedback, 385 $(61.3 \%)$ of the participants reported that they never/seldom got feedback from superiors and 314 (50.4\%) never/seldom got feedback from colleagues.

Means, SDs, and intercorrelations of all study variables are depicted in table 1. Reliabilities are presented in parentheses on the diagonal. Note that the correlations are in the anticipated direction; working time is positively associated with all stress sub-scales and negatively correlated with the recovery sub-scales (with the exception of success), whereas the feedback variables are negatively related with stress sub-scales and positively correlated with recovery sub-scales.

\section{Hierarchical regression analysis for predicting the influence of working time and performance feedback on stress and recovery sub-scales}

In order to test for the influence of workplace factors on stress and recovery in junior doctors, we conducted hierarchical regression analysis including all RESTO sub-scales and the selected workplace factors. All calculations were adjusted for age, sex, personal living situation, and having children. The results supported our hypothesis that different workplace factors influence different sub-scales of stress and recovery in our study.

We found especially overtime to be an important predictor for strain, as all strain sub-scales of the RESTQ - that is, general stress $(\beta=0.22 ; p<0.001)$, emotional stress $(\beta=0.27 ; p<0.001)$, social stress $(\beta=0.24 ; p<0.001)$, conflict $(\beta=0.31 ; p<0.001)$, fatigue $(\beta=0.25 ; \mathrm{p}<0.001)$, lack of energy $(\beta=0.12 ; \mathrm{p}<0.01)$, and physical complaints $(\beta=0.11 ; \quad \mathrm{p}<0.01)$-were statistically significantly associated with more hours of overtime. On the other hand, more feedback of superiors decreased all stress subscales (table 2). Weekend duty and feedback of colleagues were associated with single strain sub-scales (weekend duty is positively correlated with fatigue $(\beta=0.10 ; p<0.05)$, and feedback of colleagues is negatively associated with general stress $(\beta=-0.08$; $\mathrm{p}<0.05)$ and conflict $(\beta=-0.08 ; \mathrm{p}<0.05))$. With regard to the recovery sub-scales, again, overtime and feedback of superiors were important factors of influence. In this context, it is important to note that overtime $(\beta=0.10 ; p<0.05)$ as well as nightshifts $(\beta=0.13 ; p<0.05)$ show a positive association with the sub-scale 'success' (table 3 ). Furthermore, it becomes obvious that colleagues play an important part in the recovery process, as success $(\beta=0.12 ; p<0.01)$, social recovery $(\beta=0.14 ; p<0.01)$, physical recovery $(\beta=0.11 ; p<0.05)$, and general wellbeing $(\beta=0.09 ; p<0.05)$ are also statistically significantly associated with feedback of colleagues. 
Table 1 Means, SDs, and correlations of study variables

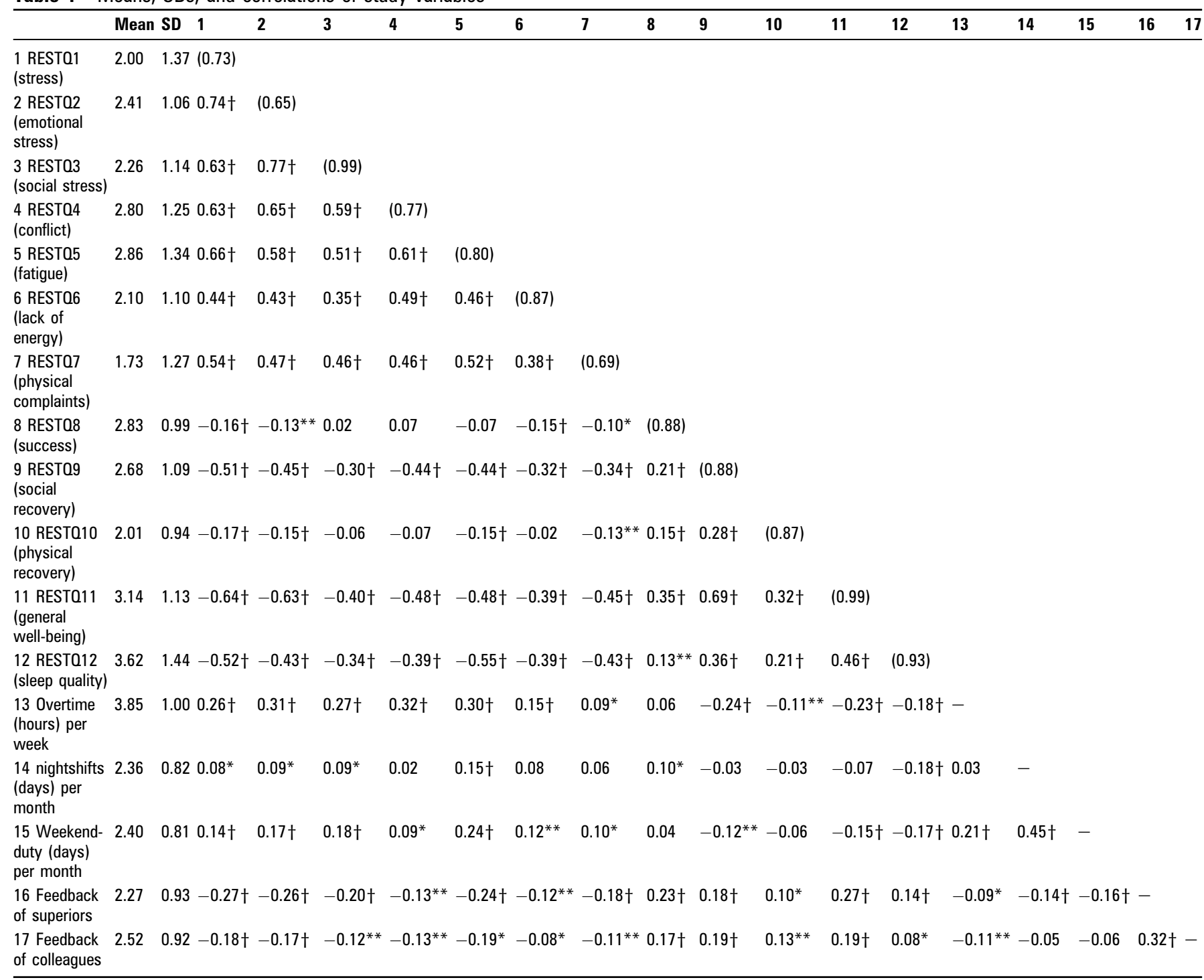

Critical values: ${ }^{*} \mathrm{p}<0.05 ;{ }^{* *} \mathrm{p}<0.01 ; \nmid \mathrm{p}<0.01$ for two-sided tests.

Cronbach's $\alpha$ reliabilities are placed on the diagonal in parenthesis. Overtime, nightshift, weekend duty, feedback of superiors, and feedback of colleagues were one-item measures.

\section{DISCUSSION}

To the authors' knowledge, this is the first study to provide a simultaneous measurement of strain and recovery in juniordoctors related to selected job specific risk factors. In general, our results support the hypothesis that overtime, nightshift, weekend duty, feedback by superiors, and feedback by colleagues each influence one or more sub-scales of the strain-recovery state of junior doctors independently and in different ways.

\section{Strain}

Specifically, all sub-scales of stress associated strain, as detected by the RESTQ, were positively related to overtime, which means that more overtime was associated with more stress

Table 2 Regression analyses for predicting RESTO stress scores (stress, emotional stress, social stress, conflict, fatigue, lack of energy, physical complaints)

\begin{tabular}{|c|c|c|c|c|c|c|c|c|c|c|c|c|c|c|c|c|c|c|c|c|c|}
\hline \multirow[b]{2}{*}{ Strain } & \multicolumn{3}{|c|}{ REST01 Stress } & \multicolumn{3}{|c|}{$\begin{array}{l}\text { REST02 Emotional } \\
\text { stress }\end{array}$} & \multicolumn{3}{|c|}{$\begin{array}{l}\text { RESTQ3 Social } \\
\text { stress }\end{array}$} & \multicolumn{3}{|c|}{ REST04 Conflict } & \multicolumn{3}{|c|}{ REST05 Fatigue } & \multicolumn{3}{|c|}{$\begin{array}{l}\text { REST06 Lack of } \\
\text { energy }\end{array}$} & \multicolumn{3}{|c|}{$\begin{array}{l}\text { REST07 Physical } \\
\text { complaints }\end{array}$} \\
\hline & $\bar{\beta}$ & SE & $\mathbf{t}$ & $\bar{\beta}$ & SE & $t$ & $\bar{\beta}$ & SE & $\mathbf{t}$ & $\bar{\beta}$ & SE & $\mathbf{t}$ & $\bar{\beta}$ & SE & $t$ & $\bar{\beta}$ & SE & $\mathbf{t}$ & $\bar{\beta}$ & SE & $\mathbf{t}$ \\
\hline Step 1: controls & \multicolumn{3}{|c|}{$\Delta R^{2}=0.012$} & \multicolumn{3}{|c|}{$\Delta R^{2}=0.008$} & \multicolumn{3}{|c|}{$\Delta R^{2}=0.006$} & \multicolumn{3}{|c|}{$\Delta R^{2}=0.006$} & \multicolumn{3}{|c|}{$\Delta R^{2}=0.003$} & \multicolumn{3}{|c|}{$\Delta R^{2}=0.012$} & \multicolumn{3}{|c|}{$\Delta R^{2}=0.035 \dagger$} \\
\hline Overtime & 0.22 & 0.06 & $5.48 \dagger$ & 0.27 & 0.04 & $6.76 \dagger$ & 0.24 & 0.05 & $5.92 \dagger$ & 0.31 & 0.05 & $7.81 \dagger$ & 0.25 & 0.05 & $6.33 \dagger$ & 0.12 & 0.05 & $2.91^{* *}$ & 0.11 & 0.05 & $2.66^{* *}$ \\
\hline Nightshift & 0.02 & 0.07 & 0.37 & 0.01 & 0.05 & 0.17 & 0.02 & 0.06 & 0.45 & 0.00 & 0.07 & 0.09 & 0.08 & 0.07 & 1.79 & 0.05 & 0.06 & 1.07 & 0.02 & 0.07 & 0.54 \\
\hline Weekend duty & 0.03 & 0.08 & 0.72 & 0.07 & 0.06 & 1.49 & 0.07 & 0.06 & 1.57 & -0.04 & 0.07 & -0.09 & 0.10 & 0.07 & $2.40^{*}$ & 0.06 & 0.06 & 1.29 & 0.05 & 0.07 & 1.13 \\
\hline Feedback colleagues & -0.08 & 0.06 & $-2.06^{*}$ & -0.07 & 0.05 & -1.84 & -0.05 & 0.05 & -1.23 & -0.08 & 0.06 & $-1.96^{*}$ & 0.01 & 0.06 & 0.28 & 0.00 & 0.05 & 0.09 & -0.04 & 0.06 & -0.94 \\
\hline
\end{tabular}


Table 3 Regression analyses for predicting RESTO recovery scores (success, social recovery, general wellbeing, sleep quality)

\begin{tabular}{|c|c|c|c|c|c|c|c|c|c|c|c|c|c|c|c|}
\hline Recovery & \multicolumn{3}{|c|}{ REST08 Success } & \multicolumn{3}{|c|}{ REST09 Social recovery } & \multicolumn{3}{|c|}{$\begin{array}{l}\text { REST010 Physical } \\
\text { recovery }\end{array}$} & \multicolumn{3}{|c|}{$\begin{array}{l}\text { REST011 General } \\
\text { wellbeing }\end{array}$} & \multicolumn{3}{|c|}{ REST012 Sleep quality } \\
\hline Step 1: controls & \multicolumn{3}{|c|}{$\Delta R^{2}=0.005$} & \multicolumn{3}{|c|}{$\Delta R^{2}=0.024^{* *}$} & \multicolumn{3}{|c|}{$\Delta R^{2}=0.007$} & \multicolumn{3}{|c|}{$\Delta R^{2}=0.009$} & \multicolumn{3}{|c|}{$\Delta R^{2}=0.014$} \\
\hline Overtime & 0.10 & 0.04 & $2.48^{*}$ & -0.21 & 0.05 & $-5.35 \dagger$ & -0.13 & 0.04 & $-3.20^{* *}$ & -0.20 & 0.04 & $-4.97 \dagger$ & -0.14 & 0.06 & $-3.52 \dagger$ \\
\hline Nightshift & 0.13 & 0.05 & $2.90^{*}$ & 0.04 & 0.06 & 0.81 & 0.01 & 0.05 & 0.21 & 0.00 & 0.06 & 0.10 & -0.14 & 0.08 & $-3.15^{* *}$ \\
\hline Weekend duty & 0.02 & 0.06 & 0.36 & -0.05 & 0.06 & -1.23 & -0.03 & 0.05 & -0.67 & -0.08 & 0.06 & -1.81 & -0.06 & 0.08 & -1.31 \\
\hline
\end{tabular}

${ }^{*} \mathrm{p}<0.05 ;{ }^{* *} \mathrm{p}<0.01 ; \dagger \mathrm{p}<0.001$

All calculations adjusted for the control variables: age, sex, personal living status, living with children younger than 15 years.

activities. This result is consistent with previous research, where longer work hours were found to be associated with greater job demands, and more psychosomatic symptoms, too. ${ }^{15}$ Umehara et al concluded that either longer working hours might lead to a feeling that job demands are greater which causes psychosomatic symptoms, or that greater job demands may increase working hours since more, or more complex, tasks need to be accomplished, which again causes psychosomatic strain.

Interestingly, there was no association between strain and nightshifts, which might be due to the fact that nightshifts are usually determined by a shift schedule and can be better planned, compared to overtime which often occurs unexpectedly. This explanation is indirectly supported by the results of Gander et al who found excessive sleepiness in junior doctors to be dependent on the frequency of changes in the schedule. ${ }^{16}$ In comparison to the lack of influence of nightshifts on strain, we found a higher frequency of weekend duties to be associated with a higher degree of fatigue. The reason for this finding is not entirely clear but may eventually be attributed to increased work-home interference.

Besides working time, all stress sub-scales were negatively related to performance feedback by direct supervisors. Moreover, general stress and conflict were also negatively associated with feedback by colleagues. Lack of performance feedback from supervisors can be generally related to a poor leadership style. Lack of performance feedback from colleagues is related to social support at the workplace. Previous research has shown these two social aspects to be of high relevance concerning physical and psychological health outcomes. The doctors participating in the study of Firth-Cozens, ${ }^{17}$ for example, perceived relationships with senior doctors to be one of the main workplace related stressors. Furthermore, Wu et al reported social support to be negatively associated with depressive symptoms. ${ }^{18}$

\section{Recovery}

Besides the influence of overtime on strain, more overtime was also related to less recovery, with the exception of the sub-scale success, where we found a positive relation to overtime. Nightshifts were also positively related to the perception of success, but negatively related to sleep quality. Other authors, too, found overtime to be related to a greater need for recovery, ${ }^{19}$ and shift and night work to be associated with shortened or disturbed sleep. ${ }^{20}$ Therefore, both factors seem to imply an increased need for recovery. ${ }^{21}$ Time spent on work related activities obviously limits the potential recovery time of an individual, and was found to be associated with subjective indicators of poor recovery (eg, difficulty to relax at home, negative affect, impaired wellbeing before bedtime, low sleep quality). ${ }^{22}$ However, the extent to which working long hours has negative health consequences may also depend on moderating variables, such as personal and work characteristics. This is mirrored in the positive association between overtime and nightshifts and success, and supports the theory that junior doctors experience overtime and nightshifts not only as strain but also as reward. These findings agree with the results of Grosch et al who found that overtime workers reported generally higher levels of participation in decision making and the opportunity to develop their own special abilities, ${ }^{23}$ two factors which are thought to be important in creating a positive work climate. ${ }^{24}$

Our analysis showed that overtime and feedback of superiors and/or colleagues have an independent and somewhat antagonistic effect on recovery activities, as performance related feedback by supervisors and colleagues were found to increase all aspects of recovery. Recent findings suggest that psychological detachment (ie, not thinking about work during off-job time) is associated with psychological recovery. The extent to which people are able to detach from work during off-job time seems to be related to work experiences. ${ }^{25}$ Based on our results, we suggest that the ability to detach from work might be influenced by performance feedback of supervisors or colleagues, as direct feedback might help to reduce the need for rumination about difficult work tasks or difficult patients during time off the job. Other researchers, too, found social support of superiors and leadership to reduce the need for recovery, ${ }^{26}$ and problematic superior support to be associated with a higher prevalence of self-reported health problems. ${ }^{27}$

\section{Limitations}

The response rate of our study was rather low, so it remains unclear if the participants of this study represent a certain subgroup of doctors who are more or less prone to strain/ recovery. The anonymous approach did not allow for evaluation of the non-respondents. Nevertheless, the overall effective response rate can be regarded as adequate for survey studies ${ }^{28}$ and corresponds to previous results of response rates of physician surveys. Another limitation is the reliance on self-reported ratings of stress and recovery by junior doctors. Thus, results may be subject to bias in terms of response style and common method variance. ${ }^{29} 30$ However, self-report was critical for understanding the impact of workplace stressors on stress and recovery experiences. Individual appraisal clearly plays a role in the findings such that participants differed in the degree to which they perceived an increased risk factor such as overtime as stressful or as impeding recovery. Finally, the cross-sectional design of the study does not allow for analysis of cause-relation effects; that is why a reversed causation effect cannot be ruled out. Future research would need to replicate the present findings in a true cross-sectional design. ${ }^{31}$ 


\section{CONCLUSIONS}

This study examines stress and recovery in junior doctors with about 1.5-2 years of work experience. To our knowledge, our study represents a new approach to the problem of stress, strain, and recovery in the focus group of junior doctors, as neither the job-strain model nor the effort-reward imbalance model-the two common occupational stress models-consider the possibilities for recovery after work. Though various other authors have already examined work related stress and strain in junior doctors, ${ }^{117}$ none of them used a simultaneous approach on both strain and recovery. Hence, this study provides new insights into the complexity of the association between workplace stressors and the individual recovery-stress state, and may help to establish effective preventive means in the future (eg, by creating 'healthy' work surroundings), and in the long term may help to address the present problem of increased mental strain in junior doctors.

Overtime and feedback by superiors seem to be especially important workplace factors for junior doctors, have independent and converse influence on stress and recovery, and are therefore to be regarded as starting points for preventive measures. Regulatory approaches have been made to reduce long working hours for doctors. Nevertheless, the positive influence of overtime on 'success' should be kept in mind. Here, it seems necessary to strike an individual balance. It might help to have role models for being successful without excessive overtime. Furthermore, an appreciative communication between superiors and employees will help to reduce stress and increase recovery in young doctors. As most clinical superiors are not specially trained for personnel management, department

\section{Main messages}

- Our study examines the simultaneous effects of workplace specific risk factors on different aspects of strain and recovery in junior doctors.

- Overtime in particular is an important stressor, which also decreases the possibilities for recovery, while performance feedback by superiors counteracts workplace stress in young doctors and, together with performance feedback by colleagues, increases recovery activities.

- Overtime and nightshifts are also signposts for being successful as a young doctor.

- Because of these results we claim that well thought through work schedules and department specific communication training might be the two most effective preventive means at the workplace when addressing mental health problems in junior doctors.

\section{Current research questions}

- Future studies on junior doctors should use a prospective design to see whether age dependent effects exist on the stress-recovery experience.

- This approach would allow investigators to test which time span, and eventually which factors of influence, diminish the increased stress of junior doctors or increase their possibilities for recovery. related communication training might bring 'on-site' help and furthermore help to counterbalance the effects of necessary overtime.

\section{Future directions}

The age distribution of our cohort was rather small, and we did not find age dependent influences. Kiss et al examined the need for recovery in employees of the public sector in Flandern, found a higher need for recovery in the youngest age category, and explained this by a lower level of experience in starting workers. ${ }^{26}$ For medical doctors, Stucky et al found decreasing emotional stress levels in the course of internship, residency, and being an attending physician. ${ }^{32}$ Future studies on junior doctors should therefore include a prospective design to see whether age dependent effects exist in the stress experience. This approach would help determine after which time span the increased stress reported by junior doctors diminishes through, for example, more experience.

Funding German Medical Association, Bavarian Medical Association.

Competing interests None declared.

Provenance and peer review Not commissioned; externally peer reviewed.

\section{REFERENCES}

1. Tyssen R, Vaglum P, Grønvold N, et al. The impact of job stress and working conditions on mental health problems among junior house officers. A nationwide Norwegian prospective cohort study. Med Educ 2000;34:374-84.

2. Tyssen R, Vaglum P. Mental health problems among young doctors: an updated review of prospective studies. Harv Rev Psychiatry 2002;10:154-65.

3. Wall TC, Bolden RI, Borrill CS, et al. Minor psychiatric disorders in NHS trust staff: occupational and gender differences. Br J Psychiatry 1997;171:519-23.

4. Firth-Cozens J. Interventions to improve physicians' well-being and patient care. Soc Sci Med 2001;52:215-22

5. Hsu K, Marshall V. Prevalence of depression and distress in a large sample of Canadian residents, inerns and fellows. Am J Psychiatry 1997;144:1561-6.

6. Girard DE, Hickman $\mathrm{DH}$, Gordon $\mathrm{GH}$, et al. A prospective study of internal residents emotions and attitudes throughout their training. Acad Med 1991;66:111-14.

7. Firth-Cozens J. Emotional distress in junior house officers. Br Med J (Clin Res Ed) 1987;295:533-6.

8. Greenberg J. Losing sleep over organizational injustice: attenuating insomniac reactions to underpayment inequity with supervisory training in interactional justice. J Appl Psychol 2006;91:58-69.

9. Hobfoll SE. Conservation of resources: a new attempt at conceptualizing stress Am Psychol 1989;44:513-24.

10. Kallus KW. Impact of recovery in different areas of application. In: Kellmann M, ed Enhancing Recovery: Preventing Underperformance in Athletes. Champaign, IL: Human Kinetics, 2002:283-300.

11. Taris TW, Beckers D, Verhoeven L, et al. Recovery opportunities, work-home interference, and well-being among managers. Eur J Work Organ Psychol 2006;12:139-57.

12. Kallus KW. Recovery-Stress Questionnaire (RESTO). (Erholungs-BelastungsFragebogen (EBF). Handanweisung]. Frankfurt: Swets Test Service, 1995

13. Kennttä G, Hassmén P. Overtraining and recovery: a conceptual model. Sports Med 1998;26:1-16.

14. Kristensen TS, Hannerz H, Høgh A, et al. The Copenhagen Psychosocial Questionnaire - $\mathrm{a}$ tool for the assessment and improvement of the psychosocial work environment. Scand J Work Environ Health 2005;31:438-49.

15. Umehara K, Ohya Y, Kawakami N, et al. Association of work-related factors with psychosocial job stressors and psychosomatic symptoms among Japanese pediatricians. J Occup Health 2007;49:467-81.

16. Gander P, Purnell H, Garden A, et al. Work patterns and fatigue-related risk among junior doctors. Occup Environ Med 2007;64:733-8

17. Firth-Cozens J. Sources of stress in junior doctors and general practitioners Yorkshire Med 1995;7:10-13.

18. Wu H, Zhao Y, Wang JN, et al. A prospective study of internal residents' emotions and attitudes throughout their training. Int Arch Occup Environ Health 2010:83:155-64.

19. van der Hulst $\mathbf{M}$, Veldhoven $\mathbf{M}$, Beckers D. Overtime and need for recovery to job demands and job control. J Occup Health 2006;48:11-19.

20. Moneta GB, Leclerch A, Chastang J, et al. Time-trend of sleep disorder in relation to night work: a study of sequential 1-year prevlaences within the GAZEL cohort. J Clin Epidemiol 1996;49:1133-41.

21. Jansen $\mathbf{N}$, Kant I, van Amelsvoort L, et al. Need for recovery from work: evaluating short-term effects of work hours, patterns and schedules. Ergonomics 2006:46:664-80.

22. Sonnentag S, Zijstra FR. Job characteristics and off-job time activities as predictors for need for recovery, well-being, and fatigue. J Appl Psychol 2006;91:330-50. 
23. Grosch JW, Caruso CC, Rosa RR, et al. Long hours of work in the U.S: associations with demographic and organizational characteristics, psychosocial working conditions, and health. Am J Ind Med 2006;49:943-52.

24. Sauter SL, Murphy LR. Organizational Risk Factors for Job Stress. Washington, DC: American Psychological Association, 1995.

25. Sonnentag S, Bayer UV. Switching off mentally: predictors and consequences of psychological detachment from work during off-job time. J Occup Health Psychol 2005;10:393-414.

26. Kiss $\mathbf{P}$, de Meester M, Braeckmann L. Differences between younger and older workers in the need for recovery after work. Int Arch Occup Environ Health 2008;81:311-20.

27. Vanroelen C, Levecque K, Louckx F. Psychosocial working conditions and selfreported health in a representative sample of wage-earners: a test of the different hypotheses of the Demand-Control-Support-Model. Int Arch Occup Environ Health 2009;82:329-42

28. Barbie ER. Survey Research Methods. Belmont, CA: Wadsworth Publishing Co, 1990.

29. Sudman S, Bradburn NM, Schwarz N. Thinking About Answers: The Application of Cognitive Processes to Survey Methodology. San Francisco, CA: Jossey-Bass, 1996

30. Tourangeau R, Rips LJ, Rasinski K. The Psychology of Survey Response. New York, NY: Cambridge University Press, 2000.

31. Zepf D, Dormann C, Frese M. Longitudinal studies in organizational stress research: a review of the literature with reference to methodological issues. J Occup Health Psychol 1996;1:145-69.

32. Stucky ER, Dresselhaus TR, Dollarhide A, et al. Intern to attending: assessing stress among physicians. Acad Med 2009;84:251-7.

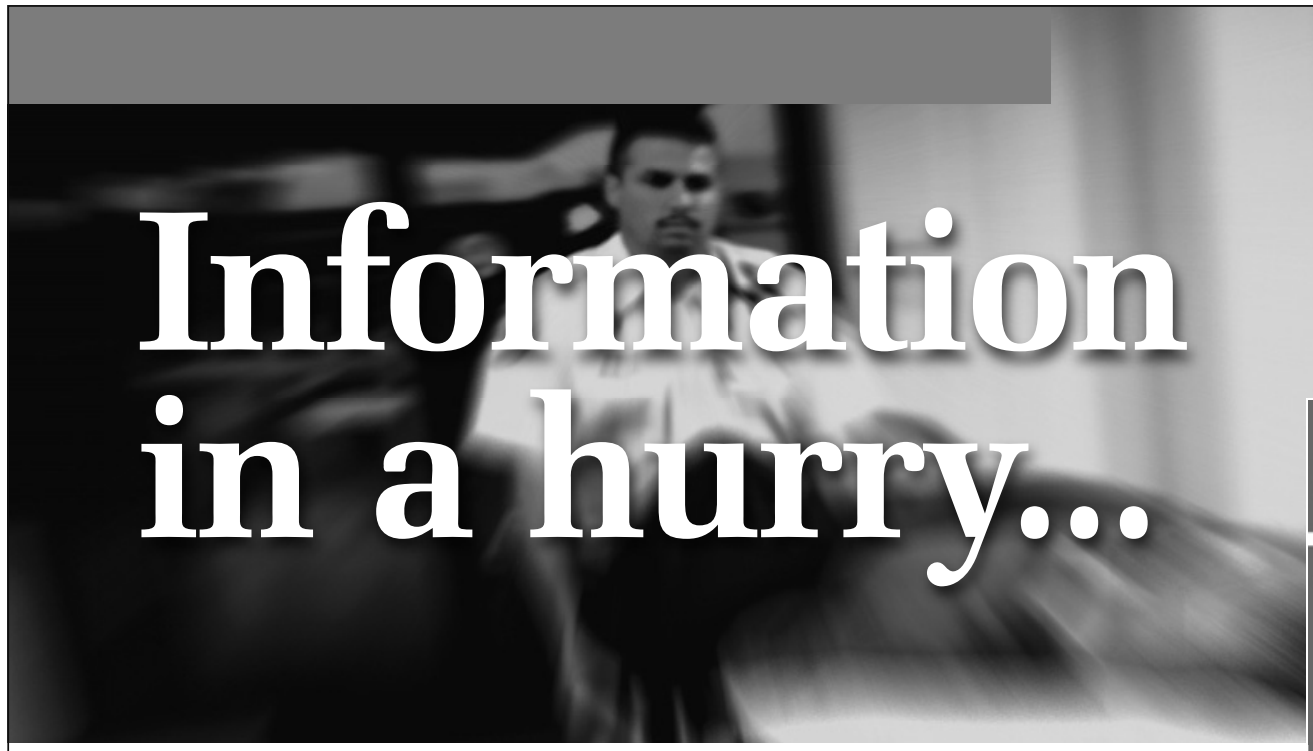

If you need the latest information in emergency care then you need the Emergency Medicine Journal. Packed with research, educational papers and debate of all aspects of emergence medicine, the journal will make sure you know everything you need to.

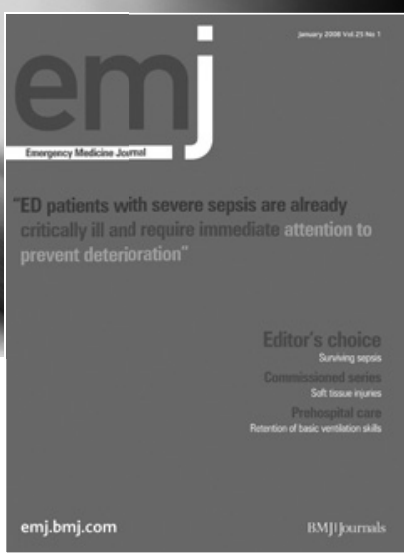

FOR MORE DETAILS OR TO SUBSCRIBE, VISIT THE WEBSITE TODAY 


\section{PMJ Stress and recovery in junior doctors}

Elke Ochsmann, Jessica Lang, Hans Drexler and Klaus Schmid

Postgrad Med J 2011 87: 579-584 originally published online March 24, 2011

doi: $10.1136 /$ pgmj.2010.103515

Updated information and services can be found at:

http://pmj.bmj.com/content/87/1031/579

These include:

References This article cites 26 articles, 3 of which you can access for free at: http://pmj.bmj.com/content/87/1031/579\#BIBL

Email alerting Receive free email alerts when new articles cite this article. Sign up in the service box at the top right corner of the online article.

Topic Articles on similar topics can be found in the following collections Collections

Patients (102)

\section{Notes}

To request permissions go to:

http://group.bmj.com/group/rights-licensing/permissions

To order reprints go to:

http://journals.bmj.com/cgi/reprintform

To subscribe to BMJ go to:

http://group.bmj.com/subscribe/ 